\title{
Analysis of Existing Approaches to Management of Industrial Enterprises
}

\author{
*Anton N. Karamyshev \\ Kazan Federal University, Naberezhnye Chelny institute of Kazan federal university \\ *Email: antonkar2005@yandex.ru
}

Received: 15th December 2017, Accepted: 20th December 2017, Published: 31st December 2017

\begin{abstract}
The management system of an industrial enterprise is the most important factor for its competitiveness. The main characteristics of the management system are the speed of making reasoned management decisions, the ability to identify the dynamics of market needs and to modify the internal environment for the purpose of producing products with the necessary characteristics within the needed times and within the limits of a determined price. There are two approaches to formation of management system: organization management (based on similar functions performed by the structural unit) and process management (based on business processes). Process approach to management involves modelling and optimization of the company's activities, modification of the management system in order to eliminate all types of losses, increase of the company's level of susceptibility to the market needs and increase of the rate of response on the part of the company's internal environment in order to meet these needs. The article describes the advantages and disadvantages of these approaches to management, offers the generalized management model based on the process approach, and also identifies the factors of higher quality of process management of an enterprise within the market economy conditions. It analyses the objectives of introducing process-based technologies, the stages of formation of the process management system, its specific features, as well as it offers the basic trends in development of processbased management within the Russian companies. The shown objectives and stages of development of process management were subjected to additional analysis, determining the main approaches to their implementation, as well as their particular aspects were shown from the author's point of view.
\end{abstract}

Keywords: Process Approach, Organization Approach, Management System, Industry, Enterprise.

\section{Introduction}

Historically, the first approach to enterprise management was the organization approach. Its essence consists in carrying out similar works within the framework of a separate structural unit (department, division, bureau). The basis for structural unit management are regulatory documents which determine its goals, objectives, organizational structure, staffing and their job descriptions.

\section{Text of Article}

Organization approach to management has the following shortcomings [1-5]:

$>\quad$ employees of structural units are focused mainly on performance of standard job responsibilities, meanwhile the necessity of performing non-standard work is often resisted by employees of structural units;

$>\quad$ employees have a poor understanding of the activities carried out in other structural divisions;

$>\quad$ work technologies in structural units are often hidden by employees, which makes it difficult to analyse their effectiveness;

$>\quad$ there is no direct motivation to master the most advanced technologies for performing works;

$>\quad$ career prospects of an employee are largely determined by the subjective assessment of the manager;

$>\quad$ analysis of effectiveness of the chain of commodity production is limited only to production and service processes;

an employee's performance evaluation is carried out by the manager subjectively due to the absence of objective individual performance targets related to the operational tasks of the enterprise;

$>\quad$ management positions are often occupied not by the most efficient employees, but by those most in line with established institutions in the corporate governance system;

$>\quad$ initiative and innovation of employees is often suppressed by managers who are afraid of career competition;

the right to make decisions belongs primarily to the managers, which leads to a loss of time for various approvals, meetings;

organization management system is quite static, which leads to a slow response to changes in market and employees' needs;

distribution of the bonus fund of the structural unit is carried out by the manager on the basis of the subjective evaluation. 
The advantage of this approach is a rigid intraorganizational hierarchy and discipline.

The second approach to management, which largely minimizes the shortcomings of the organization approach, is the process approach.

An enterprise is a set of interrelated types of works, each of which consumes resources of the enterprise (labour, material or information resources). The result of work is a certain product (material, information product or service); the result of the whole set of works - a marketable product, as well as services for its maintenance and servicing $[1,2]$.

The process approach presupposes specification of all these works and definition of their interrelations on the basis of input (consumed) and output (result) products. Interconnected works at the enterprise are a network where ridges are separate jobs, and network nodes are products. Each product can be both input and output.

Since enterprises include tens of thousands of individual jobs (and if a high degree of decomposition of business processes description is used, then hundreds of thousands), for the convenience of describing them and further analysis, individual jobs are grouped within larger elements business tasks (also called business functions), subprocesses, business processes [3]. The basis for grouping at the level of business tasks and subprocesses is a certain product with certain characteristics that is used for analysis in management accounting. Thus, the process approach involves managing a network of interconnected business processes of an enterprise.

The following important points should be noted here:

1. Identification of the business processes (the largest elements of process management) on the basis of all interrelated works of the enterprise is carried out by researchers on a random basis. This explains a great number of the existing classifications of business processes [4-6]. As a rule, the basis for business processes identification is a complex business function (logistics, production, sales, service, etc.) that is of paramount importance to business. [2,8,9].

2. The network of business processes is a selforganizing and adaptively-managed system. The consumers while buying the goods (i.e. products of the last in the network of business processes of the enterprise) force manufacturers to analyse their needs, observe an acceptable price-quality ratio, react sensitively to emergence of new products in the industry. Changes in requirements and preferences of a consumer automatically means changes in requirements for the output products of the enterprise. This leads to changes in requirements for input and output products throughout the entire network of business processes of the enterprise [10,11].

3. All business processes of the enterprise can be divided into directly and indirectly (in some cases conventionally) affecting the quality of marketable products. On the basis of this feature, all business processes of the enterprise are divided into main and auxiliary (supporting) $[8,9,11]$ ones.

The most common declared goals of implementing the process approach to management are as follows [8-11]:

1. Improving the quality of organization management on account of:

preservation of knowledge and developed technologies for performing work in business process documentation;

$>\quad$ standardization of work performed within the framework of business processes;

$>$ development of algorithms for interaction between structural divisions;

2. Reduction of the organization costs due to:

$>\quad$ elimination of duplicative actions;

$>$ optimization of logistics and production operations;

$>\quad$ elimination of unnecessary losses of time;

$>$ shortening the duration of the production cycle;

$>$ reduction of the working capital.

3. Perfection of technologies for executing business processes and their structural elements based on the analysis of the existing business processes and their modification.

4. Automation of business processes based on the information platform of the enterprise.

The studies carried out by ABPMP Russia [7] in the field of process management revealed the following trends:

a) $87 \%$ of companies documented part of their business processes; management of key business processes is carried out in $32 \%$ of companies; $13 \%$ of respondents informed about the absence of any process management elements at their enterprises;

b) $47 \%$ of companies focus on the gradual improvement of the key processes, automation of processes - $26 \%$, determination of performance indicators $-14 \%$, and $6 \%$ of respondents try to radically modify business processes;

c) the following most important objectives of the business processes were identified: regulation and standardization of processes $(68 \%)$, process automation $(54 \%)$, process optimization $(41 \%)$, quality management system implementation (24\%), operational risk management (19\%), accounting tasks (17\%).

Based on the above, the following necessary works can be defined when implementing the process approach and optimizing business processes: 
a) Modelling of business processes, their regulation and rationing of resources for performance of business tasks.

Business processes modelling is carried out in IDEF0, IDEF3, ARIS eEPC, UML and BPMN notations. Often several of these notations are used for modelling, taking into account their strengths and shortcomings [1.11].

b) Analysis and optimization of business processes that ensure the quality and necessary characteristics of marketable products.

The analysis of the main business processes (as a rule, these include production processes) can be carried out before and after modelling of business processes. The process methodologies "Lean Production" and "Six Sigma" allow partial optimization of the main business processes without their modelling in the above notations.

c) Analysis and optimization of the costs for implementing auxiliary business processes of the enterprise.

Implementation of auxiliary business processes is significantly less regulated than implementation of production processes. For this reason, in most cases, the algorithm for executing auxiliary business processes and their constituent elements represents "a black box" for managers $[3,4]$.

Optimization of supporting business processes without their modelling is problematic and is usually implemented in practice only in the form of reduction of administrative and managerial personnel and engineering staff. Functions performed by previously cut employees are allocated to the remaining staff. At the same time, the quality of performing the auxiliary business processes and the level of loading of the remaining personnel of the company are practically never predicted after such optimization, which may result in deterioration of product quality, management processes, loss of a part of the company's competencies.

Modelling and regulation of auxiliary business processes provides a basis for justifying optimization measures, calculating their economic efficiency.

d) Automation of execution of all business processes on the basis of their developed models within the framework of separate software products and information platforms.

Automation of business processes is carried out, as a rule, after modelling of business processes, because otherwise additional costs are possible for updating and finalizing the automated enterprise management system.

e) Continuous improvement of basic and auxiliary business processes.
Continuous improvement of business processes should be justified from the point of view of economic efficiency. In this context it is necessary to have an understanding how the modernization of the technologies for implementation of a separate business function will be reflected on the business process network as a whole. This understanding is possible in the presence of business process implementation models.

The works presented above are simultaneously the implementation stages of the process approach, the optimization technologies for the enterprise costs, and the elements of the management system. It is also necessary to note the possibility of both consecutive and parallel execution of some of these works.

In view of the foregoing, the following advantages of the process approach can be distinguished:

$>\quad$ opportunity to identify inefficient business processes of the enterprise with a view to making further management decisions on them;

opportunity to remove the barriers of interaction between the structural divisions of the enterprise [8,9]; orientation of all business processes of the enterprise to the needs of the end user of the product; $>\quad$ forming the basis for creating an effective mechanism for motivating the staff; regulation of algorithms for implementation of business processes provides material for their analysis and further optimization; documenting and preserving knowledge about application of the key technologies for implementation of business processes [7,10,11];

$>$ possibility of implementing effective benchmarking; increase in transparency of management decision-making for all stakeholders.

The disadvantages of the process approach to management are the following:

the necessity to regulate business processes requires specific knowledge for the groups implementing the process approach. This includes also knowledge of methodologies (notations) for describing business processes and special software products $[2,3]$;

$>$ the complexity of business processes description is sufficiently high;

$>$ resistance of the company's personnel when modelling the technologies for performing works at the enterprise. This resistance is due to a fear of change and reluctance to share one's knowledge and experience through the regulation of business processes [4,9];

$>$ the need to support the process documentation in the updated state. Such need arises in case of changes in the production nomenclature; transfer of a part of business processes into outsourcing or the external business processes into 
insourcing; changes in technology of business processes implementation.

These shortcomings of the process approach to management require the enterprise to invest in the projects for the process management system formation, but these investments, according to many researchers and senior managers, are economically justified $[2,4,7]$.

\section{Methods}

In the course of the research, the following methods were used:

1. Selective analysis of the specialized literature with the high citation index on the theme specified in the articles. In particular, it involves collection of the information on the existing management approaches. 2 . The formed array of information was systematized for the purpose of further analysis. Specifically, the article analyses the stages of implementation of process management, reveals the goals of its implementation, as well as the respective advantages and disadvantages.

3. As a result of the research work the author offered own interpretation, made the conclusions.

\section{Results}

On the basis of the given above information, the following conclusions can be drawn:

1. Process-based management is the management of a set of interrelated business processes of an enterprise, the result of which is a marketable product.

2. The process management system is adaptive-controllable, i.e. allows to effectively change the internal environment of the enterprise under the influence of the external environment.

3. The main stages in the introduction of process management are modelling, analysis, optimization, automation and continuous improvement of business processes.

4. Domestic companies show considerable interest in process management technologies. Russian enterprises implement stage-by-stage implementation of process-based management, and, currently, focus on the most important of the main and auxiliary business processes.

5. Approximately half of the respondents understand their goals in introduction of the process management as automation and optimization of business processes, which demonstrates the awareness of the stages of development of process management in the enterprise and the advantages of the process approach.

\section{Discussion}

Introduction of process management is a very labour intensive and expensive process, requiring the involvement of qualified specialists, participation of the top management of the enterprise and work of the entire enterprise personnel.
Despite all costs, introduction of process management is an economically feasible process, since it provides the basis for making more reasoned managerial decisions and automation of the management system.

\section{Conclusions}

Thus, the conducted analysis revealed the advantages and disadvantages of organization and process approaches to management. Process management technology, in comparison with the organization approach, has a number of advantages that are important within the conditions of a highly competitive environment. Introduction of the process approach allows to improve the quality of the enterprise management, reduce its costs, obtain a basis for business processes automation, analyse and improve the technologies for performing business processes.

\section{Acknowledgements}

The work is performed according to the Russian Government Program of Competitive Growth of Kazan Federal University.

\section{References}

[1] Repin, V.V., Eliferov, V.G. (2008). Process approach to management. Modeling of business processes. M.: RIA "Standard and quality".

[2] Robson, M., Ullach, F. (2003). Reengineering of business processes: practical guidance. Moscow: UNITY-DANA.

[3] Smirnov, Yu.N. (2007). Process-predetermined engineering and standard business management // Integral. № 5.

[4] Becker, J., Wilkov, L., Taratukhin, V., Kugeler, M., Rozeman, M. (2008). Process management. M.: Jaykso.

[5] Kruglov, M.G., Shishkov, G.M. (2006). Quality management. M.: JeKSMO.

[6] Harrington, D., Jesseling, K., Nimvegen, H. (2002). Optimization of business processes. Documenting, analysis, regulation, optimization. M.: The Alphabet.

[7] Koptelov, A., Filatova, M. (2015). Research of ABPMP Russia "The Russian market of BPM 2015". M.: ABPMP Russia. [Electronic resource] - URL: http://abpmp.org.ru/project/market-research/

[8] Karamyshev, A.N., Makhmutov, I.I., Utyaganov, R.F. (2015). Problems of Institutionalization of the Process-Based Management in Industrial Enterprises. International Business Management. №9(6).

[9] Makhmutov, I.I., Isavnin, A.G., Karamyshev, A.N., Sych, S.A. (2016). Classification approach in 
determination of knowledge in context of organization. Academy of Strategic Management Journal. Volume 15. Special Issue.

[10] Makhmutov, I.I., Murtazin, I.A., Isavnin, A.G., Karamyshev, A.N. (2017). The essence and types of outsourcing. International Journal of Economic Perspectives. Volume 11. Issue 3.

[11] Makhmutov, I.I., Murtazin, I.A., Isavnin, A.G., Karamyshev, A.N. (2017). Methods and models of outsourcing. International Journal of Economic Perspectives. Volume 11. Issue 3. 